\title{
Em defesa de Saúde e história
}

\author{
In defense of Saúde e história
}

Não é o crítico que julga a obra, mas a obra é que julga o crítico

Eduardo Lourenço ${ }^{1}$

Prezados editores,

Quem lê resenhas em nossos dias? Poucos leitores se dão conta da importância de um ensaio crítico sobre uma obra. Mesmo a formatação dos periódicos, particularmente nas chamadas ciências da saúde, parece negligenciar uma narrativa circunstanciada ou uma resenha de fôlego, em geral tolhidas por um número restrito de 'caracteres com espaços' e relegadas a um segundo plano pelo editor, escanteadas e escanifradas. Contudo, não deveria ser assim. Diante da atual avalanche de obras, impressas e por meio eletrônico, publicadas a torto e direito e sem critérios de qualidade, resenhas são um filtro excelente para a seleção do que se deve ler e debater. O editor de "Livros \& Redes", nesta revista, é um bravo sobrevivente, sempre em busca da excelência do ato crítico.

Mas, se falamos em ensaios de crítica, são necessárias algumas palavras de cautela. Em texto precioso, Antonio Candido abordou, há algum tempo, o 'ato crítico' em Sérgio Milliet, grande escritor, sociólogo e crítico de arte, falecido em $1966 .{ }^{2}$ Dizia Sérgio Milliet que a crítica deve ser judiciosa, unir sensibilidade e inteligência, momento racional e atitude sensível. Se seguirmos as lições de Candido e Sérgio Milliet, diremos que o ato crítico não se faz presente em resenhas magrelas e perfunctórias sobre obra e autor, dessas quase sempre encomendadas pela editora ou pelo editor, para vender seu produto. Diríamos mais, ainda juntando-nos à voz de dois dos melhores críticos brasileiros: uma resenha não deve, sobretudo, simplificar-se em críticas de tipo pontilhista, como, infelizmente, ocorreu com o curto pronunciamento de duas pesquisadoras sobre nosso livro, Saúde e história, em número recente de História, Ciências, Saúde - Manguinhos. ${ }^{3}$ A qualidade discutível da resenha sobre nosso livro e o propósito de espicaçá-lo levaram-nos a considerar a necessidade desta réplica, tendo em vista, particularmente, o fato de ser uma das autoras pesquisadora de mérito em nosso país. (A outra autora, doutoranda, terá diante de si o duro aprendizado de buscar mérito em textos dos quais pode vir a discordar).

Iniciemos nossa legítima defesa diante de uma das várias investidas, na qual, particularmente, se revelou o desconhecimento da historiografia sobre o tema no Brasil, já solidamente consolidada, inclusive por um grupo de pesquisadores da Casa de Oswaldo

\footnotetext{
${ }^{1}$ Citado por Raduan Nassar em entrevista. Fabio S. Cardoso, "O resgate de Lavoura Arcaica”, Cândido - Jornal da Biblioteca Pública do Paraná, Curitiba, n.22, p.17, maio 2013.

2 Antonio Candido, "O ato crítico", cap.8 de A Educação pela noite e outros ensaios, São Paulo, Ática, 1987.

${ }^{3}$ Silvana Maria Pereira e Joana Maria Pedro, "Saúde e história segundo Luiz Antonio de Castro Santos e Lina Faria", História, Ciências, Saúde - Manguinhos, Rio de Janeiro, v.20, n.2, p.712-716, 2013.
} 
Cruz (de cuja produção, note-se, a resenha passou batida). Referimo-nos, aqui, inicialmente, à suposta ausência de uma menção às Caixas de Aposentadorias e Pensões (CAPs), de 1923. Houve, sim, uma alusão às CAPs na abertura do texto. Nossa posição é clara e dista da posição das autoras: "as raízes mais fundas da reforma da saúde pública remontam às primeiras décadas do século 20. Não se trata das decantadas Caixas de previdência e saúde do trabalhador 'urbano', que tiveram um perfil corporativo e segmentado" (primeira contracapa, terceiro parágrafo; o destaque é nosso). Com Vargas, os serviços de saúde, bem como o início da Previdência, passaram a refletir a organização de interesses de movimentos sindicais e corporativos urbanos, de que resultaram os Institutos de Aposentadorias e Pensões (IAPs) comandados pelos chamados cardeais da previdência - os 'iapiários', criticados por Gilberto Hochman. Nos tempos de Vargas, a população rural, até então atendida por programas e serviços de profilaxia e saneamento de caráter universalista, que o Serviço Especial de Saúde Pública (Sesp) tentou manter a duras penas, perdeu a prioridade que havia conquistado nos tempos finais da Primeira República. As CAPs são um momento de inflexão em direção aos movimentos sociais urbanos organizados e revelam, pelo avesso, o descaso público em relação à população rural desorganizada, nas décadas seguintes.

Os historiadores da demografia do período citam a relação entre população urbana e rural: esta última, entre as décadas de 1930 e 1940, esteve entre 78 e 68\% da população brasileira. A população rural, até então, havia sido alvo de políticas de Estado no campo - as políticas de saúde 'pelo alto', estimuladas pela ideologia de construção nacional no início do período republicano; muito ao contrário do que supõem as autoras, essas políticas se efetivaram na 'ausência' de movimentos sociais organizados. As autoras da resenha parecem desconhecer (ver p.714 da resenha) que os direitos sociais nem sempre são conquistados "desde abajo", particularmente em países de formação histórica centralista como o Brasil.

A propósito, é falso atribuir, como fazem as autoras, um impacto efetivo sobre as políticas de saúde pelo anarcossindicalismo, à parte uma participação menor, em 1904, na rebelião contra a vacinação obrigatória: para os anarquistas daquele período, o 'vetor social' da mobilização popular no início do século passado concentrava-se não na saúde, mas nas questões operárias mais agudas (jornada de trabalho, condições de trabalho nas fábricas, salários aviltantes, trabalho infantil). Se as autoras quisessem trazer um dado histórico a seu favor, bastaria que lançassem mão da experiência do movimento sindical em Buenos Aires, nessa mesma época. Ali houve, de fato, em condições diferentes da situação brasileira, uma relação entre "salud y anarquía", para citarmos um artigo precioso do historiador Diego Armus. Mas as autoras sequer se debruçam sobre o capítulo fundamental a esse respeito, de autoria de Lina Rodrigues de Faria e Carlos Henrique Paiva. ${ }^{4}$

Em curta passagem da resenha, chama-se a atenção do leitor para a discussão de "contextos históricos e profissionais distintos, 'sem relação entre si'” (p.713; o destaque é nosso). Ora, a relação é costurada em vários capítulos, sem paralelismos fáceis ou comparações forçadas, pela preocupação de analisarmos experiências concretas, em que se projetou a difícil conquista de autonomia feminina, em diferentes tempos e territórios. No caso da experiência

\footnotetext{
${ }^{4}$ Lina Rodrigues de Faria e Carlos Henrique A. Paiva, "Saúde e doença na América Latina e no Caribe: perspectivas sociológicas e históricas", cap.10 de Luiz Antonio de Castro Santos e Lina Rodrigues de Faria (Org.), Saúde e história, São Paulo, Hucitec, 2010.
} 
das mulheres extrativistas no Maranhão, a frase da resenha, "evidenciando que a luta pela saúde nem sempre está em primeiro plano" (p.713) é curiosa, porque isto é dito como se, em alguma parte do texto, tivéssemos afirmado que ela estaria 'sempre' em primeiro plano. Ao contrário, uma leitura mais detida desse capítulo sobre as agentes comunitárias de saúde no Maranhão (cap. 5) teria apontado em outra direção e para conclusão diversa: se no início do século a relação entre saúde e anarquismo, postulada pelas autoras, não foi significativa no Brasil, tampouco a relação entre o movimento das 'quebradeiras do babaçu' e a saúde teve expressão em suas lutas, o que só ocorreria depois que enfrentaram as questões da terra e do trabalho. É o que o capitulo buscou discutir, como afirmamos nas páginas 125-126: "O que está em jogo nesta trama não é um típico 'movimento de saúde', ainda que o surgimento da solidariedade grupal, movida por outros interesses imperativos, tenha, mais tarde, aberto o caminho para as questões de saúde".

$\mathrm{Na}$ p.713, as autoras desfiguram nosso argumento sobre a história da enfermagem no Rio de Janeiro. Buscamos, na nossa p.86 e seguintes, discutir as dificuldades encontradas para a formação da enfermagem calcada no 'profissionalismo', pelo grupo de enfermeiras da Rockefeller que iria instruir as primeiras turmas da Anna Nery; tiveram de enfrentar as limitações de uma sociedade hierárquica, cujos fundamentos e exigências Carlos Chagas conhecia profundamente. Daí a busca, nos primeiros tempos, de moças de elite e normalistas, para as primeiras turmas de escola, no Rio de Janeiro, de modo a 'legitimar' o curso diante da sociedade carioca, ainda na década de 1920. O que vemos na resenha, contudo, é uma confusão entre esses dois mundos, até mesmo pela listagem da "piedade cristã" como "um parâmetro da profissionalização da enfermagem moderna" (p.713), o que em absoluto é afirmado por nós. A ênfase na formação católica da Anna Nery se explicava - isto está dito no texto - pela preocupação da Igreja com o protestantismo das enfermeiras de Mary Parsons. Nossa afirmação, que vem logo a seguir no texto, é desprezada pelas autoras. Dizíamos, na p.88: "Na prática, o profissionalismo iria prevalecer, como a análise das disciplinas teóricas e práticas ministradas na Anna Nery desde os primeiros tempos nos revela".

A relação entre saúde e política nos Estados Unidos, ainda nas primeiras décadas do século $\mathrm{XX}$, é bastante complexa. As autoras pinçam - é o termo, infelizmente - um aspecto de tal relação, e silenciam sobre outros. O aspecto ressaltado é o trabalho das visitadoras, destinadas às populações imigrantes e pobres, e consideradas "ameaça à saúde pública americana" (nota 7, p.715 da resenha). Contudo, nas páginas 162 e seguintes, sobre as quais as autoras silenciam, há um importante contraponto - o lado permeável às reformas profundas da sociedade americana no curto tempo em que o chamado progressivism pôde germinar. Naquelas páginas, discutimos o experimento social pioneiro de Wilbur C. Philips em Nova Iorque e em Milwalkee, que permitiu e estimulou a participação da comunidade - hoje em dia a isso chamamos impropriamente controle social - nos primeiros centros de saúde naquelas cidades. Logo em seguida à página selecionada pelas autoras, enfatizamos a experiência socialista da prefeitura de Milwalkee entre 1910 e 1912, passageira, mas geradora de fortes movimentos sociais e de reformas na saúde pública dali em diante, antes que a onda do 'perigo vermelho' se alastrasse na política norte-americana. Como as autoras silenciam sobre esses germens de mudança social e política, não teriam a chave explicativa para entender, nas décadas seguintes, o surgimento de um movimento participativo e militante das social workers - profissionais 
do serviço social, como Charlotte Stern, líder que chegou a ser presa, em Nova Iorque, por atividades antiamericanas e de organização sindical, durante o macarthismo.

Um filtro simplificador é também aplicado à nossa discussão da enfermagem internacional. As autoras silenciam sobre a relação entre líderes da enfermagem da Europa e dos Estados Unidos e o movimento sufragista feminista, que procuramos (em vão!) destacar. No tocante à ação militante daquelas pioneiras, dedicamos uma longa passagem às lutas de Lavinia Dock, militante feminista do National Women's Party e secretária do International Council of Nurses, no front norte-americano, que se somavam às campanhas de Ethel Bedford Fenwick pela autonomia e organização da profissão, na Inglaterra. Mas as resenhistas preferiram negligenciar essa dimensão de um luta social, para citar, em seu lugar, um comentário passageiro de inspiração racista de Lavinia. A historiografia sobre esse longo período conhece a força da 'biologia' das chamadas raças superiores e do racialismo em toda a primeira metade do século XX. Quem, nos movimentos ideológicos emancipatórios, inclusive no interior do marxismo - senão o próprio Marx - pôde livrar-se por inteiro do fardo racista? ${ }^{5}$

Nossa discussão sobre a formação da enfermagem provocou perguntas intempestivas das resenhistas, que uma leitura moldada sob o 'ato crítico' teria evitado: a formação em saúde pública contribuiu para uma qualificação "verdadeiramente (sic) científica", ou produziu na enfermagem uma "autonomia ficcional"? (p.714). Nossa discussão, nas páginas 88-90, resulta de uma crítica a certa historiografia da enfermagem, que fala em "intenções veladas" das autoridades sanitárias, tornando a análise de políticas concretas um jogo de adivinhação; ou procura estabelecer nexos determinantes entre economia e saúde, em que pese a relação extremamente variada entre o capital e o campo da saúde, particularmente em períodos anteriores à emergência do capitalismo monopolista. Nossa discussão procurou colocar a questão num outro nível, em que o cenário social e econômico servia de parâmetro para limitações de todo tipo, mas não gerava exercícios 'ficcionais' no mundo das profissões. Nosso capítulo 4, sobre as profissões supostamente subalternas - a exemplo da enfermagem -, pede mais ao historiador ou à historiadora do que falsas oposições e conclusões chapadas. O tratamento que demos ao papel da Rockefeller, em alguns capítulos, mereceu das autoras uma interrogação que já continha as respostas, como um juízo preconcebido: a Fundação Rockefeller "representou efetivamente um avanço para o país ou reproduziu os modelos de medicina social formulados nos países centrais e exportados para as 'colônias'?" (p.715 da resenha). A nosso juízo, seria uma tarefa de primeira ordem se as autoras tentassem analisar, do ponto de vista histórico-comparativo, o que sucedia, na época, entre as colônias africanas - que de fato sofriam um transplante da medicina social dos países centrais - e entre os países da periferia do capitalismo como o Brasil. O livro de Lina Rodrigues de Faria Saúde e política: a Fundação Rockefeller e seus parceiros em São Paulo ${ }^{6}$ é uma primeira sugestão de leitura às autoras, sobre São Paulo. Não houve ali mera reprodução ou transplante, mas germinação, criação e parcerias (como entre Samuel Pessoa e Wilson Smillie, que pesquisavam, atuavam juntos como sanitaristas e publicavam em dupla). A experiência no Rio de Janeiro não foi diferente:

\footnotetext{
${ }^{5}$ Sugerimos às autoras a leitura de uma obra fundamental sobre a força da 'eugenia' no interior do campo ideológico europeu - inclusive nas Américas -, durante os séculos XIX e XX: Mark B. Adams (Ed.), The wellborn science: eugenics in Germany, France, Brazil, and Russia, New York, Oxford University Press, 1990. Infelizmente a obra não foi traduzida para o português até hoje.
} 
salta aos nossos olhos a mirada simplista de nossas avaliadoras, que teriam feito das carreiras científicas de Manguinhos, anteriores mesmo à vinda da Rockefeller, um simples exercício de copiar e colar modelos externos.

A discussão histórica da resenha nos surpreende ao apresentar alguns autores (Conill, Mendes, entre outros) que trariam abordagens que 'destoam' das nossas, pois, a rigor, são autores que de fato não focalizaram os períodos e temas estudados em nosso livro, salvo como referência passageira ou pano de fundo. Uma citação, no entanto, merece comentário. As autoras referem-se aos estudos de Maria Martha de Luna Freire (2008) ${ }^{7}$ como se conflitassem com nossas perspectivas de análise e interpretação: "outro enfoque", afirmam na p.715. Para nós essa afirmação é igualmente surpreendente, pois bastaria às autoras uma leitura atenta do artigo citado, para se aperceberem de que não somente Martha Freire situa o ideário da maternidade científica na década de 1920 como "parte do amplo projeto reformador republicano com vista à constituição da nacionalidade" (Freire, 2008, p.153), algo que defendemos sem hesitar, mas dialoga conosco ${ }^{8}$ em seu estudo competente e esclarecedor.

Há sugestões e pontos relevantes na resenha, para reflexão e futuro trabalho de pesquisa. Entre esses, a enfermagem latino-americana exige estudos mais detidos, de natureza histórico-comparativa. Outro ponto, em particular, diz respeito ao impacto internacional da Fundação Rockefeller no pós-guerra, ainda pouco debatido no Brasil. Referimo-nos particularmente aos vetores das mudanças na orientação da Rockefeller, no pós-guerra, que merecem pesquisas adicionais, como as que ora se realizam no Museu Histórico Carlos da Silva Lacaz, da Universidade de São Paulo, sobre as articulações entre a Rockefeller e o ensino, a pesquisa e a atenção à saúde.

Last but not least, um fecho de agradecimento às autoras se impõe, em primeiro lugar por nos ter levado a reler - e a trazer aos leitores de História, Ciências, Saúde-Manguinhos - o texto magnífico de Antonio Candido sobre o ato crítico; em segundo lugar, por nos ter dado a oportunidade de agradecer à editora executiva, Roberta Cardoso Cerqueira, e ao editor de "Livros \& Redes", Carlos Henrique Assunção Paiva, a permissão de publicar uma réplica em História, Ciências, Saúde - Manguinhos, que igualmente se impunha.

Luiz Antonio de Castro Santos Professor do Departamento de Políticas e Planejamento em Saúde/ Universidade Estadual do Rio de Janeiro

Lina Rodrigues de Faria Professora do Departamento de Medicina e Fisioterapia/ Universidade Federal de Juiz de Fora

\footnotetext{
${ }^{6}$ Lina Rodrigues de Faria, Saúde e política: a Fundação Rockefeller e seus parceiros em São Paulo, Rio de Janeiro, Editora Fiocruz, 2007.

${ }^{7}$ Ver Maria Martha de Luna Freire, "Ser mãe é uma ciência": mulheres, médicos e a construção da maternidade científica na década de 1920, História, Ciências, Saúde-Manguinhos, Rio de Janeiro, v.15, supl., p.153-171, 2008.

${ }^{8}$ Ver Luiz Antonio Castro Santos, "O pensamento sanitarista na Primeira República: uma ideologia de construção da nacionalidade", Dados - Revista de Ciências Sociais, Rio de Janeiro, v.28, n.2, p.193-210, 1985 e Luiz Antonio Castro Santos e Lina Rodrigues de Faria, "Os primeiros centros de saúde nos Estados Unidos e no Brasil: um estudo comparativo", Teoria e Pesquisa, São Carlos, v.40/41, p.137-181, 2002.
} 